\title{
Expressivity and musical shape in turntablism: Response to Greasley and Prior
}

\author{
KJETIL FALKENBERG HANSEN \\ KTH Royal Institute of Technology, Sound and Music Computing
}

\begin{abstract}
This commentary on Greasley and Prior's paper "Mixtapes and turntablism: DJs' perspective on musical shape" extends the findings of the study by looking at the turntablism perspective. First, a general discussion on the study's method and background is given. Then, the role of turntables as musical instruments in creating musical shape is outlined. Finally, some relationships between turntablism techniques, expressive performances and musical shape are presented. In general, the findings in the study support previously published studies in this insufficiently researched area.
\end{abstract}

Submitted 2013 May 17; accepted 2013 May 27.

KEYWORDS: scratching, turntablism, expressivity, musical instruments, $D J$

IN "Mixtapes and turntablism: DJs' perspectives on musical shape" Greasley and Prior present an interview-based study with three semi-professional DJs to reveal their understanding and employment of "shape" and "shaping" in their expressive music performances. During the interviews, the DJs performed with instructions given by the investigators, and created new musical compositions in an improvisational style. The main findings of the study were that this group of musicians, often without formal musical schooling, has an intuitive concept of shape in music that is comparable to that of classical instrumentalists, and that shape is an integral part of playing expressively. Moreover, to play expressively, the participating DJs appeared to incorporate turntablism techniques more actively.

This commentary extends and discusses some findings in the study by looking more closely at the turntablism aspect. Seemingly — and only based on casual everyday observations - turntablism still represents for many people a fairly nontypical music style with a set of playing rules that may appear esoteric and unfamiliar. Therefore, I will relate musical shaping to perspectives on 1) how turntables can be said to have become musical instruments in their own right, and 2) the musical cues DJs tend to use to create expressive performances. First, however, there are some matters in the Greasley and Prior paper that should be covered.

\section{DEFINITIONS}

The authors' applications of the terms turntablism and turntablist are valid although not straightforward. They mention turntablism techniques and turntablism as a musical style, but without supplying explanations. Furthermore, only two of the four participating DJs in the study, including the DJ from the earlier questionnaire study (Prior, 2012), are identified as turntablists, although they are all observed using the turntables as musical instruments. Finally, the first author presents herself as a DJ with extensive experience, but not a turntablist, while her Soundcloud profile lists several turntablists as inspiration for her own DJ practice. This confusion is symptomatic of a recurring debate in the DJ community since the term "turntablist" was introduced in 1995. In the debate, most agree that a turntablist is a DJ that has moved beyond the ordinary role and become a musician playing the turntable (typically the instrument consists of two turntables and mixer). However, many oppose the notion of turntablism as a musical direction, just as we never talk about "guitarism". To DJs and initiated listeners these confusions are of little concern, but for the discussion it is better to provide definitions.

If not all DJs are called turntablists, and turntablists are characterized by treating turntables as musical instruments, the implication is that there are certain playing styles that can be attributed to this 
group-hence the differentiation between turntablism and DJing. For the sake of simplicity for the contribution by Greasley and Prior, as well as this commentary, a turntablist is simply a musician playing the turntables and mixer, and generally what is called a DJ here. Likewise, turntablism does not mean a specific music genre, but a collection of playing styles and techniques common to DJs which can be used in any music genre. These styles and techniques include among others scratching and beat juggling which for many are the essence of turntablism, and mixing, which for many is the act of changing records. The techniques are not exclusive, but to some extent hierarchical: mixing, at the highest level, can contain elements of scratching or beat juggling, and beat juggling can contain scratch elements. A fundamental description of the techniques is given below (for a comprehensive overview of turntables used as musical instruments and an introduction to hip-hop DJ culture, see Katz, 2012).

These definitions have influence on two other important terms from the study: the mixtape and the equipment. The participants were not explicitly asked to make a mixtape-like performance, but from the instructions, equipment and analysis it is reasonable to assume that all related this task to how a mixtape could be made. However, producing a mixtape normally involves an exploratory stage of finding material and less improvisation (Reighley, 2000). The term "turntablism" does not exclusively mean playing vinyl records on turntables, but encompasses DVS (digital vinyl systems) and other devices that allow a scratching-like interaction. It is therefore not a big concern that all three participants in the study had different equipment: in fact, the musically most "conservative" of the DJs from a turntablist perspective did not use turntables at all, but CD players.

\section{EXPERIMENTAL METHOD AND PROCEDURE}

The same experimental procedure of producing three performances with unfamiliar songs was run for the participating DJs: first without instruction, then with shape and finally without shape, and all followed by interviews. One DJ played a familiar song, however, and one DJ used DVS equipment (Denon and Serato) with visual representation of the song and the possibility of setting cue points. As such, the conditions were quite different even if the procedure was the same. Again, these possible problems do not jeopardize the results very much, especially when it was the most conservative DJ who used the DVS, while the most typical mix DJ used only vinyl; if it was the other way around there would be more reason for concern.

For the performances, the DJs were given few instructions and they appeared to be somewhat puzzled by them. This observation matches experiences from previous experiments conducted by Hansen, Fabiani, and Bresin (2011) where DJ participants showed some difficulty interpreting expressions and terms commonly used in research on tune-based or classical music. Even playing expressively to match emotional descriptions ("play with sadness") needed in many cases further explanations or consultation. The results reported by Greasley and Prior should be read with this problem of instruction in mind: the discussion in-between the two conditions "with shape" and "without shape" may have changed their conception of "shape". In their second performance (with shape), none of the DJs changed much from the first performance, whilst in the third (without shape), they reduced all parameters like EQ, song structure and playing techniques to a minimum. In effect, the discussion of shape commenced with two extreme and unfamiliar situations, much unlike the respondents in the previous study (Prior, 2012) who had mostly classical backgrounds, and where the vast majority reported using the term in their practice. Also unlike other instrumentalists who can visually inspect a score quickly, they needed some time to recognize features of the music by listening.

\section{TURNTABLES AS MUSICAL INSTRUMENTS}

There is no categorical divide between turntables as playback devices and as musical instruments. They are conclusively instruments when turntablists perform live. But, it is also possible to create new music by only moving the pickup around between the tracks, and, arguably, to create new music by playing two existing recordings simultaneously without manipulating them further, or physically manipulating the vinyl records but playing the record back in a standard fashion on the turntable (Ferguson \& Marclay, 2003).

From a technical point of view, the simplest, and also most common, equipment offers a limited set of sound-making and sound-changing possibilities, quite comparable to a traditional instrument like the 
guitar (Beamish, 2004; Hansen \& Bresin, 2006). The DJ can choose the sound material (select recording, select where to play in the recording), set amplitude (crossfader, channel/up fader), set pitch (move record, adjust pitch slider), change timbre (equalization). Combining these features, onset and offset control is ample, but the characteristics of the recording dictate and often limit tone duration and pitch control. Timbre control is restricted to adjustments in the "high", "medium" and "low" frequency areas. These conditions apply to all the different playing techniques, from mixing and beat juggling to scratching and drumming.

In terms of interaction, the instrument provides visual, tactile and auditory feedback. The visual is restricted to inspecting the vinyl, level meters and the positions of the pickup, knobs and sliders, while the only tactile feedback comes from direct touch. The audio mixers have two separate out channels, which means it is possible to play one record through the monitors and listen to the other with headphones.

The set-ups used by participants in the study consisted of more advanced equipment than outlined above; Matt used an advanced mixer, the Pioneer DJM-600, Rich had DVS (turntables and Serato) but was instructed not to use it, and Tony used a Rane 61 mixer and Denon SC3900 CD players connected to Serato and did use the additional functionality offered by DVS. The main advantages of DVS systems are the digital storage of music, an excellent visual representation on the screen, a BPM count estimator, and fast access to cue points. Excepting these conveniences, using ordinary turntables or DVS does not differ much. The Pioneer DJM-600 mixer has a BPM count estimator, indication for when two tracks are in sync, recording and playback of samples with pitch and tempo modulations, and several digital audio effects and filters.

For reasons still to be disclosed, the turntablism community has always been conservative and unwilling to accept "shortcuts" to virtuosity: for instance, the DMC World Championships did not allow DVS until 2011 although a majority of DJs already used it (Katz, 2012; DMC World DJ Championships, 2012). It is therefore interesting to learn that playing without shape meant partly using fewer playing techniques (scratching and beat juggling), and partly refraining from using EQ controls to even-out or juxtapose the timbres, even when they all primarily related shape to the larger-scale composition of the mix. If musical shape really was understood as the large-scale composition the results would have shown that the DJs "decomposed" the tunes by for instance playing verses, intros and other defined parts in an unstructured order. Now, as it seems, shaping is done on the smaller scale and confirms the assumption of turntables as being musical instruments.

\section{EXPRESSIVE PERFORMANCES}

In previous studies, we have seen that DJs are good at expressing different musical intent with the same set of scratching techniques and in a similar way (Hansen, Bresin, \& Friberg, 2008; Hansen, Fabiani, \& Bresin, 2011). These studies also reveal differences and similarities between turntables and other musical instruments in emotional performance strategies (Juslin, 2001; Friberg, Bresin, \& Sundberg, 2006). Typically, DJs use rather small variations in their playing gestures, which results in a narrow range of expression, especially to the untrained listener. We believe this can be explained by the general impression many have of the hip-hop genre which is probably not that of expressing a wide variation of emotions.

Finally, a distinguishing feature of turntablism is the dominance in improvisational performance of a short, looped beat, often repeated for minutes. This can readily be heard in commercially available records, and also seen in Figure 8 in the Greasley and Prior article, where 45 King's track normally used for scratching to is plotted as a wave form. To give musical shape to compositions based on a looped background, the DJ can mainly rely on trained, technical skills and a developed sense of musical detail. This assumption, arguably, is supported in the presented paper.

\section{REFERENCES}

Beamish, T. (2004). A taxonomy of DJs, the online taxonomy of DJ practice. http://www.timothywisdom.com/djtaxonomy.php.

DMC World DJ Championships. (2012). DMC World DJ competition history. 
http://www.dmcdjchamps.com/about.php.

Ferguson, R., \& Marclay, C. (2003). Christian Marclay. Los Angeles: UCLA Hammer Museum.

Friberg, A., Bresin, R., \& Sundberg, J. (2006). Overview of the KTH rule system for musical performance. Advances in Cognitive Psychology: Special Issue on Music Performance, Vol. 2, Nos. 2-3, pp.145-161.

Hansen, K.F., \& Bresin, R. (2006). Mapping strategies in DJ scratching. In: Proceedings of the Conference on New Interfaces for Musical Expression. Paris: IRCAM, Centre Pompidou, pp. 188-191.

Hansen, K.F., Bresin, R., \& Friberg, A. (2008). Describing the emotional content of hip-hop DJ recordings. In: Proceedings of Neuroscience and Music III, Montreal.

Hansen, K.F., Fabiani, M., \& Bresin, R. (2011). Analysis of the acoustics and playing strategies of turntable scratching. Acta Acustica united with Acustica, Vol. 97, pp. 303-314.

Juslin, P.N. (2001). Communicating emotion in music performance: a review and theoretical framework. In: P.N. Juslin \& J.A. Sloboda (Eds.), Music and Emotion. New York: Oxford University Press, pp. 309-337.

Katz, M. (2012). Groove Music: The Art and Culture of the Hip-hop DJ. New York: Oxford University Press.

Prior, H.M. (2012). Report for questionnaire participants. http://www.cmpcp.ac.uk/Prior_Report.pdf.

Reighley, K.B. (2000). Looking for the Perfect Beat: The Art and Culture of the DJ. New York: MTV Books/Pocket Books. 